\title{
MEIS1 and its potential as a cancer therapeutic target (Review)
}

\author{
MAOZHONG YAO ${ }^{1}$, YONG GU $^{1}$, ZHAOXIN YANG ${ }^{2}$, KEYAN ZHONG $^{2}$ and ZHANJUAN CHEN ${ }^{3}$ \\ ${ }^{1}$ Clinical Research Center, Hainan Provincial Hospital of Traditional Chinese Medicine, Guangzhou University \\ of Chinese Medicine, Haikou, Hainan 570203; ${ }^{2}$ Teaching Experimental Animal Center, Research Center for \\ Drug Safety Evaluation of Hainan Province, Hainan Medical University; ${ }^{3}$ Chemical Experiment Teaching Center, \\ College of Pharmacy, Hainan Medical University, Haikou, Hainan 571199, P.R. China
}

Received December 15, 2020; Accepted July 8, 2021

DOI: $10.3892 /$ ijmm.2021.5014

\begin{abstract}
Meis homeobox 1 (Meis1) was initially discovered in 1995 as a factor involved in leukemia in an animal model. Subsequently, 2 years later, MEIS1, the human homolog, was cloned in the liver and cerebellum, and was found to be highly expressed in myeloid leukemia cells. The MEIS1 gene, located on chromosome 2p14, encodes a 390-amino acid protein with six domains. The expression of homeobox protein MEIS1 is affected by cell type, age and environmental conditions, as well as the pathological state. Certain types of modifications of MEIS1 and its protein interaction with homeobox or pre-B-cell leukemia homeobox proteins have been described. As a transcription factor, MEIS1 protein is involved in cell proliferation in leukemia and some solid tumors. The present review article discusses the molecular biology, modifications, protein-protein interactions, as well as the role of MEIS1 in cell proliferation of cancer cells and MEIS1 inhibitors. It is suggested by the available literature MEIS1 has potential to become a cancer therapeutic target.
\end{abstract}

\section{Contents}

1. Introduction

2. Molecular biology of MEIS1

3. Modification

4. Protein-protein interactions

5. Role of MEIS1 in the proliferation of cancer cells

6. MEIS1 inhibitors

7. Conclusions and future perspectives

Correspondence to: Professor Zhanjuan Chen, Chemical Experiment Teaching Center, College of Pharmacy, Hainan Medical University, 3 Xueyuan Road, Longhua, Haikou, Hainan 571199, P.R. China E-mail: 29856961@qq.com

Key words: Meis homeobox 1, molecular biology, modification, protein interaction, cell proliferation of cancer, potential as therapeutic target

\section{Introduction}

The Meis homeobox 1 (Meis 1 ) gene was initially discovered as a common viral integration site in the BXH-2 mouse model of leukemia in 1995 (1). Subsequently, after 2 years, the human homolog (MEIS1) was cloned in the liver and cerebellum, and was found to be highly expressed in myeloid leukemia cells (2). Two pro-viral integration clusters exist between two regions located $90 \mathrm{~kb}$ apart, and the MEISI gene alone was found between the two clusters (3). The MEIS1 gene encodes a $3.8 \mathrm{~kb}$ transcript with an open reading frame that encodes a homeodomain protein (4).

Homeobox protein MEIS1 belongs to the three amino acid loop extension (TALE) homeodomain transcription factor family, whose members also include MEIS2 and MEIS3 (5). MEIS2 protein comprises of 477 amino acids and has a molecular weight of $51,790 \mathrm{Da}$. This protein is coded by the MEIS2 gene, that has a length of $212,108 \mathrm{bp}$. The MEIS3 protein is coded by the MEIS3 gene with a length of $19,110 \mathrm{bp}$ and is composed of 375 amino acids. The potential interplay between the two proteins and MEIS1, is illustrated in Fig. 1 (modified from www.string-db.org/).

MEIS1 is involved in a number of physiological and pathophysiological processes; most notably, in cell migration, apoptosis and metabolism. The present review article summarizes the results of previous studies that have implicated MEIS1 in cancer cell proliferation. The potential use of MEIS1 as a novel biomarker and therapeutic target in cancer was also discussed.

\section{Molecular biology of MEIS1}

DNA/RNA. MEIS1 is located between LOC729348 and LOC100507073 on chromosome 2 p14, and contains the anonymous markers, D2S134 and NIB1519 $(2,6)$. It consists of 13 exons and 137,360 bp (6). The 3' untranslated region (3' UTR) of MEISl is highly conserved during evolution (7). The structure of the MEIS1 gene is illustrated in Fig. 2. In total, four MEIS1 isoforms, produced by alternative splicing, have been described: MEIS1a, MEIS1b, MEIS1c and MEIS1d (6). MEIS1a possesses all 13 exons, whereas MEIS1b lacks the 95-bp exon 12 (4). MEIS1c lacks 49 amino acids (Val 162 to Gln 210) and is expressed in mouse embryos (8). MEIS1d lacks exon 8 and is expressed in mouse colorectal cancer cells (9). 
A linear diagram of MEIS1 isoforms with their exons is presented in Fig. 3.

The full-length MEIS1 mRNA consists of 3,198 bp (6). The expression of MEIS1 mRNA in different human tissues, according to the Human Protein Atlas (http://www.proteinatlas.org/), is illustrated in Fig. 4. The highest expression levels of MEIS1 mRNA are found in the endometrium, fallopian tubes and smooth muscle, whereas the lowest levels are found in skeletal muscle, liver and bone marrow.

Protein. Full-length MEIS1 consists of 390 amino acids and has a molecular weight of 43,016 Da (6). MEIS1 contains a pre-B-cell leukemia homeobox (PBX)1 interaction domain, serine/threonine-rich domain, aspartic acid/glutamic acid-rich domain, poly-aspartic acid domain, homeodomain and transcriptional activation domain (10). The conserved PBX interaction motif, homeodomain and $\mathrm{C}$-terminal region are critical for leukemic transformation (11).

MEIS1 is localized mainly in the nucleus (12), although its expression has also been detected in the cytoplasm in certain tumor cells, such as in ovarian cancer cells (13). During pregnancy, MEIS1 localizes to the cytoplasm and the membrane of endometrial glandular epithelial cells (14).

Relative MEIS1 expression at the protein level in different human tissues, according to the Human Protein Atlas, is illustrated in Fig. 5. The highest expression of MEIS1 occurs in the fallopian tubes and smooth muscle. However, a previous study suggested that MEIS1 was expressed at highest levels in the endo- and myometrium among 87 types of normal tissues (15).

In addition to the pathological state, other factors such as cell type, age and environmental conditions also affect MEIS1 expression. MEIS1 is highly expressed in all cell lines with a mixed-lineage leukemia (MLL) mutation, but not in wild-type MLL cell lines (16). The expression of MEIS1 in solid tumors is somewhat paradoxical, as it is overexpressed in certain tumor types, whereas it is downregulated in others (5). The cell types from the different organ sites under investigation (5) and the types of metabolism (10) the cancer cells require may be responsible for these contradicting findings. MEIS1 tends to be expressed at higher levels in fetal hearts than in adult hearts (17); however, another study reported a lower MEIS1 expression in postnatal hearts than in adult hearts (18). Among pediatric patients with acute lymphoblastic leukemia (ALL), MEIS1 expression is more frequent in infant ALL than in childhood ALL (19). The discrepancies among these studies, particularly, the association of MEIS1 with age, requires further investigation. Hypoxia has been shown to reduce the expression of MEIS1 in the heart (20), and to downregulate MEIS1 expression in pulmonary artery smooth muscle cells in both primary culture and animals (21).

\section{Modification}

MEIS1 related modifications include DNA methylation and protein ubiquitination. These are discussed below.

DNA methylation. The hypomethylation of the MEIS1 promoter mediated by DNA methyltransferase 3A (DNMT3A) has been observed in acute myeloid leukemia (AML) without MLL fusions (22). In AML involving the AML-RUNX1 partner

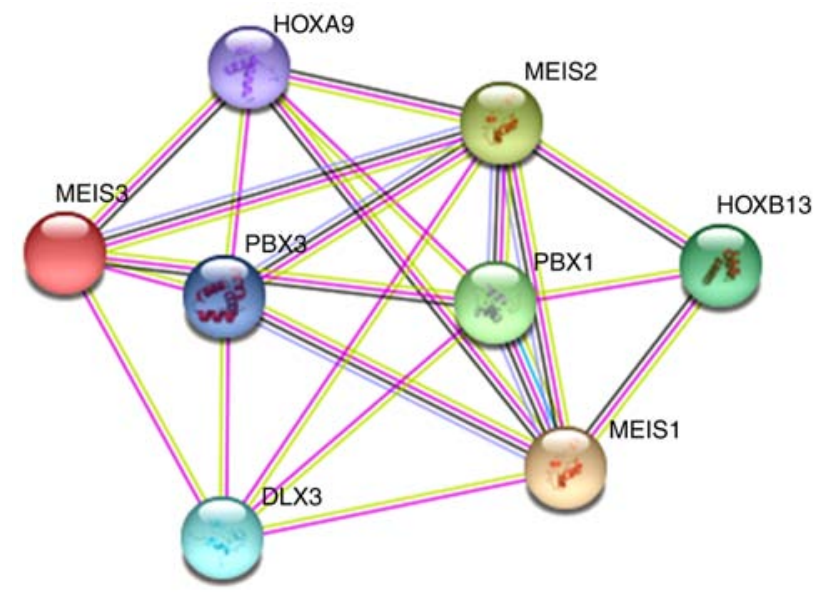

Figure 1. Potential interplay between MEIS2, MEIS3 and MEIS1. The data shown were modified from the STRING database (www.string-db. org). MEIS1, Meis homeobox 1; MEIS2, Meis homeobox 2; MEIS3, Meis homeobox 3; HOXA9, homeobox A9; HOXB13, homeobox B13; PBX1, pre-B-cell leukemia homeobox 1; DLX3, distal-less homeobox 3.

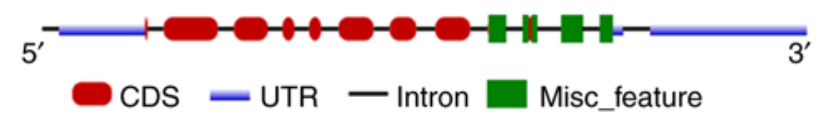

Figure 2. Structure of the MEIS1 gene. MEIS1, Meis homeobox 1; CDS, coding sequence; UTR, untranslated regions.

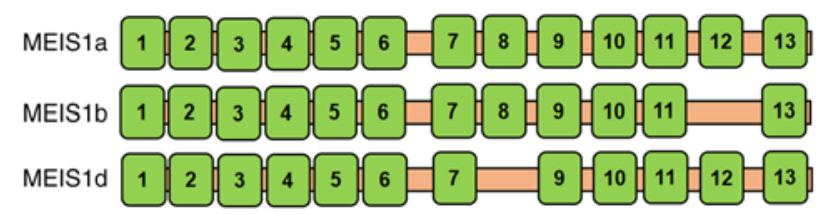

Figure 3. Linear diagram of MEIS1 isoforms with their exons (green boxes). MEIS1, Meis homeobox 1.

transcriptional co-repressor 1 (ETO) fusion, the hypermethylation of the MEIS1 promoter causes the transcript level to decrease with time (23). MEIS1 downregulation can be reversed by the combination of the demethylating agent, decitabine, and the histone deacetylation inhibitor, trichostatin A (23). Although no methylation of the MEIS1 promoter has been observed in patients with AML (24), trimethylation mediated by SET domain bifurcated histone lysine methyltransferase 1 (SETDB1) or the complex of polymerase-associated factor 1 (PAF1) and SETDB1 (25), has been detected. Thus, modifications of the MEIS1 gene differ across types of AML. MEIS1 gene methylation has also been observed in solid tumors, such as bladder cancer (26). The methylation level of the MEISI promoter is significantly associated with MEISI downregulation in the B-raf proto-oncogene (BRAF)p.v600e mutant human colon cancer tissues and colon cancer cell lines (27). However, another study using colorectal cancer tissues from 42 patients failed to detect the methylation of the MEIS1 promoter (28).

Ubiquitination. Protein ubiquitination promotes its degradation (29). The exposure of hematopoietic stem cells to branched-chain amino acid (BCAA) has been shown to 


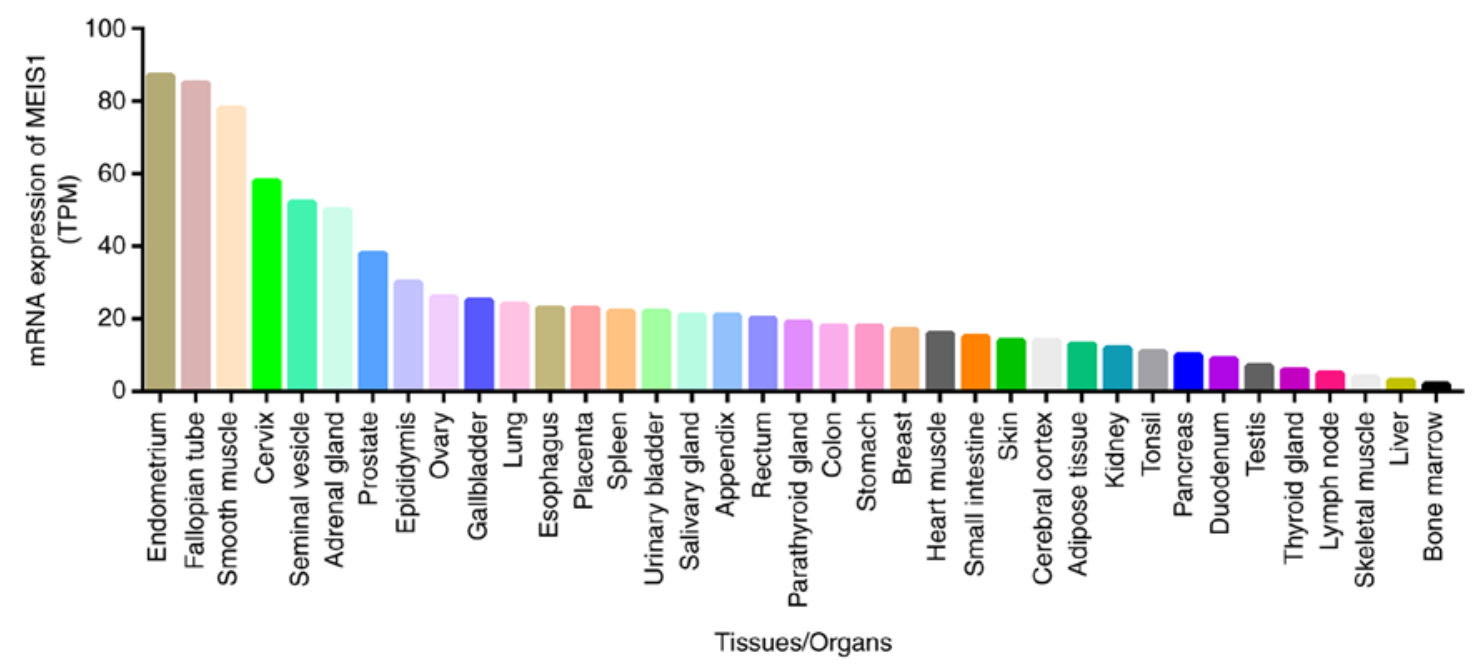

Figure 4. Expression of MEIS1 mRNA in different human tissues. The data shown were derived from The Human Protein Atlas (http://www.proteinnatlas. org/). MEIS1, Meis homeobox 1; TPM, transcripts per kilobase million.

increase the cell division cycle 20 (CDC20)-mediated ubiquitination of MEIS1 protein (30). Conversely, the competitive inhibition of E3 binding to MEIS1 by PBX3 prevents the ubiquitination of MEIS1 (31).

\section{Protein-protein interactions}

Protein-protein interactions play crucial roles in cellular functions and biological processes. MEIS1 is known to interact with several partners, including homeobox (HOX) and PBX proteins.

HOX protein family. MEIS1 binds to HOXA9 to form a heterodimeric complex (32), which in turn binds to target DNA sequences that contain the MEIS1 binding site (TGACAG) and an AbdB-like HOX site (TTTTACGAC) (33). HOXA10, HOXA11, HOXD12 and HOXB13 can also form DNA-binding complexes with MEIS1b (33). In mouse embryos, both HOXA13 and HOXD13 interact with MEIS1a C-terminal domain (18 amino acids) and MEIS1b C-terminal domain (93 amino acids) (34). HOX protein stabilizes the interaction between MEIS1 and its target DNA; as a result, target DNA dissociates at a markedly slower rate from the MEIS1-HOX complex than from MEIS1 alone (33). The overexpression of MEIS1 induces cell apoptosis through caspase-dependent processes, whereas the overexpression of MEIS1 and HOXA9 inhibits apoptosis and protects cells from the influence of apoptosis-inducing factors (35).

MEIS1 and HOX can also bind to a third protein to form trimers. For example, MEIS1 forms a trimer with HOXA9 and PBX2 in myeloid leukemia cells, which then binds to the target DNA (36). Trimers formed by MEIS1, HOXA10 and PBX2 mediate the expression of target genes in the human endometrium (37).

$P B X$ protein family. PBX proteins located in the nucleus are significantly associated with MEIS1 expression (38). PBX1 and MEIS1 form a dynamic dimer, with each protein binding to its respective target DNA site (39). A cyclic adenosine monophosphate (cAMP)-responsive sequence (CRS1) in the bovine cytochrome $\mathrm{P} 450$ family 17 (CYP17) gene is a transcriptional regulatory element that contains binding sites for $\mathrm{PBX}$ and MEIS1. PBX1 and MEIS1 bind cooperatively to CRS1 to regulate cAMP-dependent transcription, whereas neither protein can bind this element on its own (40). The dimers formed by PBX1 and MEIS1 can also bind to the PBX/MEIS binding site in the SRY-box transcription factor 3 (SOX3) promoter, where they regulate $S O X 3$ expression during development (41).

PBX-regulating protein-1 (PREP1) controls the expression of MEIS1 through post-transcriptional regulation: PREP1 inhibits the interaction between PBX1 and MEIS1 in mouse embryonic fibroblasts, destabilizing MEIS1 and inhibiting the interaction between MEIS1 and DEAD-box helicase $3 \mathrm{x}$-linked (DDX3x) and DDX5, and ultimately decreasing MEIS1 tumorigenicity (42). Dimerization with PBX3 stabilizes MEIS1, allowing it to upregulate target genes, such as FMS related receptor tyrosine kinase 3 (FLT3) and tribbles pseudokinase 2 (TRIB2), thereby enhancing HOX9-mediated transformation. MEIS1 protein that does not bind to $\mathrm{PBX} 3$ is prone to ubiquitination and subsequent degradation. Mutations in the PBX binding region in MEIS1 can also prevent the ubiquitination of MEIS1, as PBX3 and the responsible E3 ubiquitin ligase share common binding requirements within MEIS1 $(30,43)$.

MEIS1 can form trimers with PBX protein, as well as HOX protein. MEIS1 in megakaryocytes binds to PBX1b and PBX2 to form MEIS1/PBX complexes, which in turn binds to the TGACAG sequence in tandem repeats of the MEIS1 binding element (TME) of the platelet factor 4 (PF4) promoter, inducing the expression of the gene. The simultaneous overexpression of MEIS1 and PBX2 potentiates the activation of the PF4 promoter, and is abrogated when the MEIS1 binding site on the TME is destroyed (44).

\section{Role of MEIS1 in the proliferation of cancer cells}

As a transcription factor, MEIS1 functions as a positive regulator of the proliferation of leukemia cells (45), as well as in certain solid tumors, such as esophageal squamous cell carcinoma (46), malignant peripheral nerve sheath (47) and Ewing sarcoma (48); however, it has also been shown to function as a 


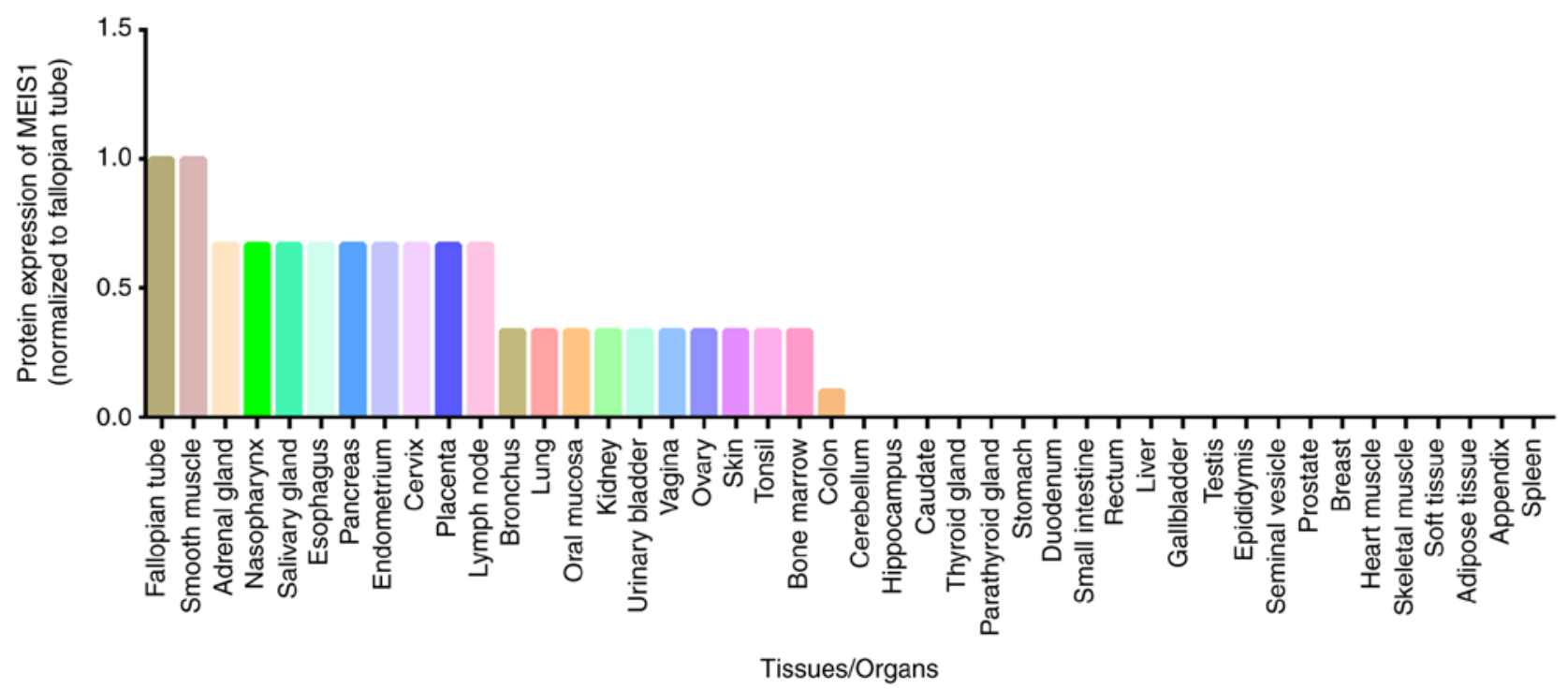

Figure 5. Relative MEIS1 expression at the protein level in different human tissues. The data shown were derived from The Human Protein Atlas (http://www. proteinatlas.org/). MEIS1, Meis homeobox 1.

negative regulator of several other solid tumors (49) (Fig. 6 and Table I). A schematic diagram of the promoting and inhibitory roles of MEIS1 in various types of cancer is presented in Fig. 6.

Leukemia. MEIS1 interacts with a variety of partners to promote the proliferation of leukemia cells. Recent studies have demonstrated that MEIS1 interacts with HOXA9 to promote cell proliferation in leukemia via synaptotagmin-like 1 (SYTL1) (50), cyclin D3 (CCND3) (51) or spleen tyrosine kinase (Syk) (52). In patients with acute AML, the interaction between MEIS1 and HOXA9 induces the proliferation of leukemia cells via the simultaneous overexpression of MEIS1 and HOXA9 $(31,52,53)$, suppresses granulocyte colony-stimulating factor (G-CSF)-induced granulocytic differentiation and promotes cell proliferation via stem cell factor (SCF) (54). In addition, the complex formed by MEIS1 and HOXA9 is recruited to the FLT3 promoter to turn on the gene (55), and FLT3 induces mitogen-activated protein kinase (MAPK) phosphorylation, inhibits apoptosis and promotes leukemia cell proliferation (56). The MEIS1-HOXA9 complex also interacts with TRIB1 to induce MAPK phosphorylation, and to stimulate leukemia cell proliferation (57). A recent study demonstrated that the MEIS1-HOXA9 complex bound to the endothelin receptor type $\mathrm{A}$ (EDNRA, a tumor promotor) promoter in leukemia cells, resulting in cell proliferation and in resistance to apoptosis (58). HOXD13 also helps regulate the pro-proliferative function of MEIS1 in AML. The human leukemia-specific fusion gene NUP98-HOXD13 (ND13) has myeloproliferative activity, although it does not directly induce AML in mice (59). However, when MEIS1 expression is upregulated, ND13 can induce cell proliferation and generate AML in transplanted mice (59). PBX also functions as a cofactor of MEIS1 to regulate leukemia cell proliferation. Immortalized progenitor cells induced by HOXA9 typically do not undergo leukemic transformation; however, the co-expression of MEIS1 and PBX can induce FLT3 expression, increase MAPK phosphorylation and promote leukemic transformation (60). The co-expression of MEIS1 and PBX3 can transform normal

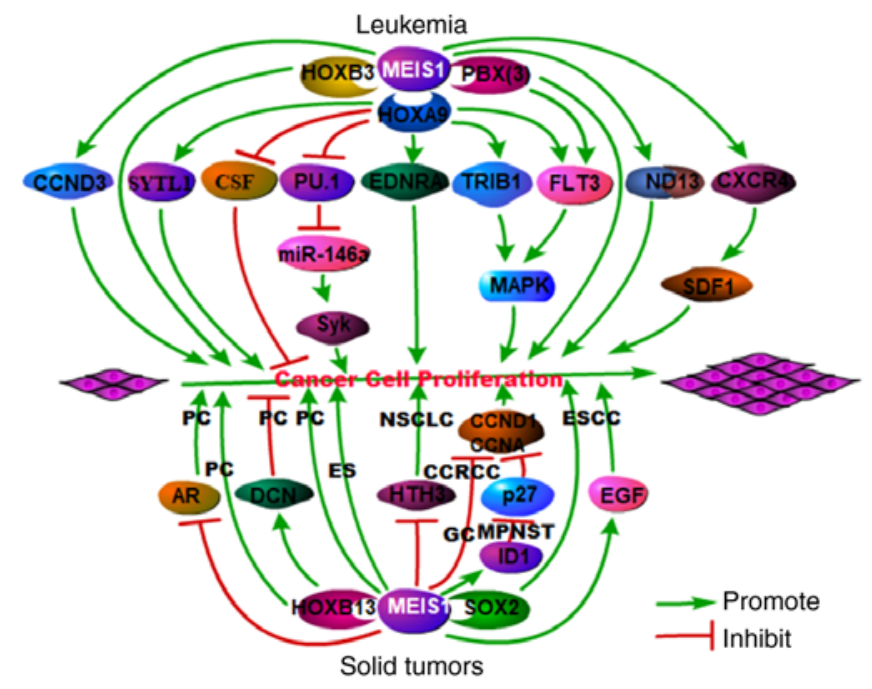

Figure 6. Schematic diagram of the promoting and inhibitory roles of MEIS1 in various types of cancer. Leukemia is illustrated in the upper panel, while solid tumors are presented in the lower panel. MEIS1, Meis homeobox 1; HOXB3, homeobox B3; HOXA9, homeobox A9; PBX3, pre-B-cell leukemia homeobox 3; CCND3, cyclin D3; SYTL1, synaptotagmin-like 1; CSF, colony-stimulating factor; PU.1, spi1; EDNRA, endothelin receptor type A; TRIB1, tribbles pseudokinase 1; FLT3, receptor tyrosine kinase 3; ND13, NUP98-HOXD13; CXCR4, C-X-C motif chemokine receptor 4; Syk, spleen tyrosine kinase; MAPK, mitogen-activated protein kinase; SDF1 (CXCL12), $\mathrm{C}-\mathrm{X}-\mathrm{C}$ motif chemokine ligand 12; PC, prostate cancer; ES, ewing sarcoma; NSCLC, non-small cell lung cancer; CCND1, cyclin D1; CCNA, cyclin A; CCRCC, clear cell renal cell carcinoma; ESCC, esophageal squamous cell carcinoma; AR, androgen receptor; DCN, decorin; HTH3, histone H3; GC, gastric cancer; MPNST, malignant peripheral nerve sheath tumor; ID1, inhibitor of DNA binding 1; EGF, epidermal growth factor; HOXB13, Homeobox B13; SOX2, SRY-box transcription factor 2.

hematopoietic stem/progenitor cells in vitro and induce AML (leukemia cell proliferation) in mice (61). MEIS1 is also involved in MLL. MEIS1 regulates the differentiation arrest, cycle activity, in vivo invasion and self-renewal of MLL cells, and thus represents a key limiting factor of MLL stem cell potential (62). The downregulation of MEIS1 and HOXA alters 
Table I. Roles of MEIS1 in cancer cell proliferation.

\begin{tabular}{|c|c|c|c|c|c|}
\hline Disease & Cell type & $\begin{array}{c}\text { MEIS1 } \\
\text { expression }\end{array}$ & $\begin{array}{l}\text { Role of } \\
\text { MEIS1 in } \\
\text { proliferation }\end{array}$ & $\begin{array}{c}\text { MEIS1 } \\
\text { interacting } \\
\text { partner }\end{array}$ & (Refs.) \\
\hline Leukemia & H9M1 & $\uparrow$ & Promote & HOXA9 & $(50)$ \\
\hline Leukemia & Bone marrow cell lines & $\uparrow$ & Promote & - & $(51)$ \\
\hline Leukemia & Myeloid progenitors & $\uparrow$ & Promote & HOXA9 & $(52)$ \\
\hline Leukemia & Myeloid clonogenic progenitor & $\uparrow$ & Promote & HOXA9 & $(32,53)$ \\
\hline Leukemia & Bone marrow progenitors & $\uparrow$ & Promote & HOXA9 & (54) \\
\hline Leukemia & Hematopoietic progenitors & $\uparrow$ & Promote & HOXA9 & $(55)$ \\
\hline Leukemia & Primary leukemia cells & $\uparrow$ & Promote & HOXA9 & $(57)$ \\
\hline Leukemia & Bone marrow cell lines & $\uparrow$ & Promote & HOXA9 & $(58)$ \\
\hline Leukemia & Myeloid clonogenic progenitor & $\uparrow$ & Promote & - & $(59)$ \\
\hline Leukemia & Hematopoietic progenitors & $\uparrow$ & Promote & PBX & $(60)$ \\
\hline Leukemia & Hematopoietic stem/progenitor cells & $\uparrow$ & Promote & PBX3 & $(61)$ \\
\hline Leukemia & Precursor B-cell leukemic line, RS4 & $\uparrow$ & Promote & - & $(63)$ \\
\hline Prostate cancer & $\begin{array}{l}\text { Human prostate cancer cells, } \\
\mathrm{LNCaP} \text { and } \mathrm{PC}-3\end{array}$ & $\downarrow$ & Inhibit & - & $(49)$ \\
\hline Prostate cancer & Human prostate cancer cells, $\mathrm{LNCaP}$ & $\downarrow$ & Inhibit & - & $(64)$ \\
\hline Prostate cancer & Human prostate cancer cells, DU145 & $\uparrow$ & Promote & HOXB13 & $(65)$ \\
\hline Prostate cancer & Human prostate cancer cells, DU145 & $\downarrow$ & Inhibit & HOXB13 & $(66)$ \\
\hline Non-small cell lung cancer & A549 cells & $\downarrow$ & Inhibit & - & $(67)$ \\
\hline Gastric cancer & Human GC cell line, MKN28 & $\downarrow$ & Inhibit & - & $(68)$ \\
\hline $\begin{array}{l}\text { Clear cell renal cell } \\
\text { carcinoma }\end{array}$ & $\begin{array}{l}\text { Human ccRCC cell lines, } 786-O \text { or } \\
\text { Caki-1 }\end{array}$ & $\downarrow$ & Inhibit & - & (69) \\
\hline $\begin{array}{l}\text { Esophageal squamous cell } \\
\text { carcinoma }\end{array}$ & Human KYSE-30 ESCC cells & $\uparrow$ & Promote & SOX2 & $(46)$ \\
\hline $\begin{array}{l}\text { Esophageal squamous cell } \\
\text { carcinoma }\end{array}$ & Human KYSE-30 ESCC cells & $\uparrow$ & Promote & - & (70) \\
\hline $\begin{array}{l}\text { Malignant peripheral nerve } \\
\text { sheath }\end{array}$ & MPNST cell line, STS26T & $\uparrow$ & Promote & - & $(47)$ \\
\hline Ewing sarcoma & $\begin{array}{l}\text { Ewing sarcoma cell lines, A673, } \\
\text { SKNMC and TC32 }\end{array}$ & $\uparrow$ & Promote & - & (48) \\
\hline
\end{tabular}

MEIS1, Meis homeobox 1; HOXA9, homeobox A9; PBX, pre-B-cell leukemia homeobox; SOX2, SRY-box transcription factor.

C-X-C motif chemokine receptor 4 (CXCR4)/stromal cell derived factor 1 (SDF-1) signaling to inhibit the proliferation of transplanted mutant MLL-rearranged acute leukemia cells (63), again supporting a pro-proliferative role of MEIS1 in MLL.

Solid tumors. MEIS1 has been associated with a variety of solid cancers, including prostate, non-small cell lung and gastric cancer, as well as clear cell renal cell carcinoma, esophageal squamous cell carcinoma, malignant peripheral nerve sheath tumors and Ewing sarcoma. The MYC-mediated downregulation of MEIS1 upregulates the androgen receptor (AR) to promote prostate cancer cell proliferation (64). AR transcription is inhibited by the overexpression of MEIS1 and is promoted by MEIS1 knockdown with small interfering RNA (49). A proposed mechanism is that MEIS1 interacts with AR to affect the trafficking of androgen between the cytoplasm and nucleus. In this manner, MEIS1 may inhibit prostate cancer cell proliferation by regulating AR, since this receptor plays a key role in proliferation of human prostate cancer cells. MEIS1 also participates in prostate cancer through mechanisms independent of AR. Recent studies have indicated that MEIS1 regulates the proliferation of prostate cancer cells by interacting with MEIS-interacting domains in HOXB13 (65), which induces decorin (DCN), a multi-RTK inhibitor (66). MEIS1 knockdown has been shown to significantly increase the proliferation of non-small cell lung cancer cells through a mechanism related to DNA synthesis and histone $\mathrm{H} 3$ phosphorylation (67). MEIS1 expression is reduced in human gastric cancer and clear cell renal cell carcinoma, and MEIS1 overexpression inhibits cell proliferation by decreasing CCND1 and CCNA expression $(68,69)$. In contrast to its inhibitory roles, MEIS1 maintains the stem cell status and cell proliferation through interaction with SOX2 in esophageal squamous cell carcinoma cells (46). The downregulation of MEIS1 upregulates epithelial markers and downregulates epidermal growth factor (EGF), a 
Table II. Basic information about MEIS1 inhibitors.

Name/code

Chemical structural formula

Type of MEIS1

inhibited action

Effect

(Refs.)

MI-2

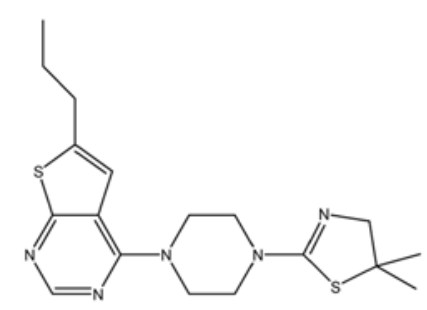

MI-503

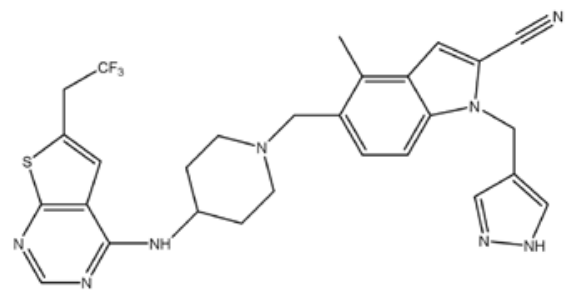

MI-3454

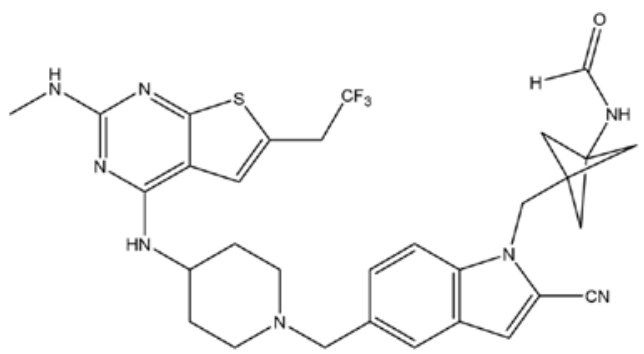

Compound 9e<smiles>Cc1cc(C)cc(NC(=O)NCCCCCCCN(P)c2nc(C)cc(Nc3ccc4nc(C)cc(N)c4c3)n2)c1</smiles>

CCI-007<smiles>CCOC(=O)COc1ccc(/C=C2\SC(=N)NC2=O)cc1OC</smiles>

MEISi-1

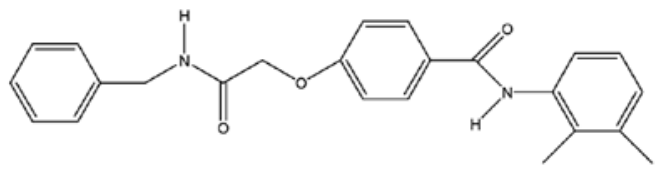

MEISi-2

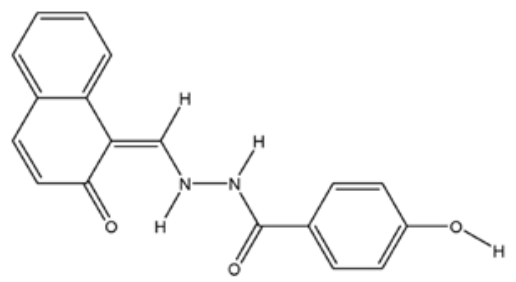

Anti-proliferative effects in MLL cells

Indirect

Inhibitory effects on MLL cells

Indirect

Anti-proliferative effect in acute leukemia cells and primary patient samples with $M L L 1$ translocations or NPM1 mutations

Indirect

Anti-proliferative activities against leukemia cells

Indirect

Cytotoxic activity against infant leukemia in $M L L-r$

Direct Modulated activity in hematopoietic stem cell via inhibiting MEIS1 directly

Direct Anti-proliferative activity in hematopoietic stem cell via inhibiting MEIS1 directly

MEIS1, Meis homeobox 1; MLL, mixed-lineage leukemia; NPM1, nucleophosmin 1; MLL-r, mixed-lineage leukemia-rearranged; MLL-FPs, mixed-lineage leukemia-fusion proteins.

marker of cell proliferation (70). In malignant peripheral nerve sheath tumors, MEIS1 expression is increased and promotes cell proliferation and maintains cell survival by inhibiting the cell cycle suppressor, $\mathrm{p} 27$, via transcription factor inhibitor of DNA binding 1 (ID1) (47). In Ewing sarcoma, MEIS1 collaborates with EWS-FLI1 to stimulate cell proliferation (48). 


\section{MEIS1 inhibitors}

Since MEIS1 plays an important pro-proliferative role in leukemia and certain solid tumors, it has the potential for use as a therapeutic target. MEIS1 inhibitors under development for treatment of cancer are reviewed and listed in Table II.

Menin-MLL inhibitors have an anti-proliferative function via MEIS1 in leukemia cells. MI-2 is a first-generation small molecule inhibitor of the Menin-MLL interaction, but has poor pharmacological profiles (71). The second-generation inhibitor, MI-503, is highly potent and orally bioavailable, and has been shown to exert profound anti-proliferative effects in MLL cells (72). The cytotoxic concentration of these compounds in cells was $>2 \mu \mathrm{M}$ and the relatively modest effect in vivo suggested limited druggability (73). The third generation inhibitor, MI-3454, is well-tolerated and does not impair normal hematopoiesis in mice; however, it inhibits the proliferation and induces the differentiation of acute leukemia cells by downregulating MEIS1 and FLT3 indirectly (74). VTP-50469, another type of highly selective oral Menin-MLL inhibitor, appears to promote leukemia cell differentiation and inhibit cell proliferation through the indirect downregulation of MEIS1 (75-77). All Menin-MLL inhibitors mentioned above are reversible in nature. To achieve an optimal anti-leukemic activity, extended drug exposure is required (78). M-525, a highly potent and irreversible Menin-MLL inhibitor, has been shown to inhibit the proliferation of and suppress MEIS1 expression in MLL cells at a sub-nanomolar concentration (78), indicating that the downregulation of MEIS1 with Menin-MLL inhibitors may represent a promising therapeutic strategy for MLL. In addition to Menin-MLL inhibitors, certain other agents that downregulate MEIS1 indirectly can exert anti-proliferative effects in leukemia cells. For instance, the proton pump inhibitor, rabeprazole, selectively suppresses the proliferation and induces the apoptosis of leukemia cells harboring MLL fusion proteins by downregulating MEIS1 (79). The DOT1-like histone lysine methyltransferase (DOT1L) inhibitor compound, 9e (80), and the MLL-rearranged leukemia inhibitor, CCI-007 (81), also produce similar effects via MEIS1-dependent mechanism.

In a recent study, two small molecule MEIS1 inhibitors (MEISi-1 and MEISi-2) were identified using high-throughput in silico screening, and induced hematopoietic stem cell expansion (82).

\section{Conclusions and future perspectives}

The present review article summarized the characteristics of MEIS1, its role in cancer cell proliferation and the current status on the development of MEIS1 inhibitors as therapeutic agents. MEIS1 is upregulated and mediates cell proliferation in leukemia and certain solid tumors (e.g., esophageal squamous cell carcinoma and malignant peripheral nerve sheath tumors), whereas it inhibits cell proliferation in other solid tumors. Agents that inhibit MEIS1 directly or indirectly are being developed. MEIS1 is increasingly recognized as a marker of cancer diagnosis and a therapeutic target.

The paradoxical role of MEIS1 among solid tumors (stimulatory in some but inhibitory in others) warrants further investigation. Illustrating the potential association between the Warburg effect, cancer cell proliferation and MEIS1 may resolve this contradiction, as the Warburg effect plays an important role in cell proliferation (83). Designing MEIS1 inhibitors based on the molecular structure of MEIS1 may expedite the developmental process of anticancer agents.

\section{Acknowledgements}

Not applicable.

\section{Funding}

The present review article was supported by the Key Research and Development Plan of Hainan Province (grant no. ZDYF2019196) and the Innovation and Entrepreneurship Training Program for college students at the Hainan Medical University (grant no. X202011810017).

\section{Availability of data and materials}

Not applicable.

\section{Authors' contributions}

MY drafted the manuscript. ZC conceived the study and participated in the manuscript preparation. $\mathrm{ZY}$ and $\mathrm{KZ}$ assisted in the literature search and edited the manuscript. YG revised the manuscript. ZC and MY confirm the authenticity of all the raw data. All authors have read and approved the final manuscript.

\section{Ethics approval and consent to participate}

Not applicable.

\section{Patient consent for publication}

Not applicable.

\section{Competing interests}

The authors declare that they have no competing interests.

\section{References}

1. Moskow JJ, Bullrich F, Huebner K, Daar IO and Buchberg AM: Meis1, a PBX1-related homeobox gene involved in myeloid leukemia in BXH-2 mice. Mol Cell Biol 15: 5434-5443, 1995.

2. Smith JE, Bollekens JA, Inghirami G and Takeshita K: Cloning and mapping of the MEIS1 gene, the human homolog of a murine leukemogenic gene. Genomics 43: 99-103, 1997.

3. Nakamura T, Largaespada DA, Shaughnessy JD Jr, Jenkins NA and Copeland NG: Cooperative activation of hoxa and Pbx1-related genes in murine myeloid leukaemias. Nat Genet 12: 149-153, 1996.

4. Steelman S, Moskow JJ, Muzynski K, North C, Druck T, Montgomery JC, Huebner K, Daar IO and Buchberg AM: Identification of a conserved family of Meis1-related homeobox genes. Genome Res 7: 142-156, 1997.

5. Jiang $\mathrm{M}, \mathrm{Xu} \mathrm{S}, \mathrm{Bai} \mathrm{M}$ and Zhang A: The emerging role of MEIS1 in cell proliferation and differentiation. Am J Physiol Cell Physiol 320: C264-C269, 2021.

6. Torres-Flores J and Jave-Suárez L: MEIS1 (Meis homeobox 1). Atlas Genet Cytogenet Oncol Haematol: 424-429, 2013. 
7. Su ZH, Si WX, Li L, Zhou BS, Li XC, Xu Y, Xu CQ, Jia HB and Wang QK: MiR-144 regulates hematopoiesis and vascular development by targeting meis1 during zebrafish development. Int J Biochem Cell Biol 49: 53-63, 2014.

8. Knoepfler PS, Calvo KR, Chen H, Antonarakis SE and Kamps MP: Meis1 and pKnox1 bind DNA cooperatively with $\mathrm{Pbx} 1$ utilizing an interaction surface disrupted in oncoprotein E2a-Pbx1. Proc Natl Acad Sci USA 94: 14553-14558, 1997.

9. Crist RC, Roth JJ, Waldman SA and Buchberg AM: A conserved tissue-specific homeodomain-less isoform of MEIS1 is downregulated in colorectal cancer. PLoS One 6: e23665, 2011.

10. Aksoz M, Turan RD, Albayrak E and Kocabas F: Emerging roles of Meis1 in cardiac regeneration, stem cells and cancer. Curr Drug Targets 19: 181-190, 2018.

11. Mamo A, Krosl J, Kroon E, Bijl J, Thompson A, Mayotte N, Girard S, Bisaillon R, Beslu N, Featherstone M and Sauvageau G: Molecular dissection of Meis1 reveals 2 domains required for leukemia induction and a key role for hoxa gene activation. Blood 108: 622-629, 2006.

12. Dintilhac A, Bihan R, Guerrier D, Deschamps S, Bougerie H, Watrin T, Bonnec $G$ and Pellerin I: PBX1 intracellular localization is independent of Meis1 in epithelial cells of the developing female genital tract. Int J Dev Biol 49: 851-858, 2005.

13. Crijns APG, de Graeff P, Geerts D, Hoora KAT, Hollemac H, van der Sluis T, Hofstrad RMW, de Bock GH, de Jong S, van der Zeea AGJ and de Vries EGE: MEIS and PBX homeobox proteins in ovarian cancer. Eur J Cancer 43: 2495-2505, 2007.

14. Li HX, Guo XY, Xie Y, Yuan QL, Ge MX and Zhang JY: Study of the dynamic expression of Meis1 in mice. Iran J Reprod Med 11: 139-144, 2013

15. Xu B, Geerts D, Qian K, Zhang H and Zhu G: Myeloid ecotropic viral integration site 1 (MEIS) 1 involvement in embryonic implantation. Hum Reprod 23: 1394-1406, 2008.

16. Quentmeier H, Dirks WG, Macleod RAF, Reinhardt J, Zaborski M and Drexler HG: Expression of HOX genes in acute leukemia cell lines with and without MLL translocations. Leuk Lymphoma 45: 567-574, 2004.

17. Locatelli P, Belaich MN, López AE, Olea FD, Vega MU, Giménez CS, Simonin JA, Bauzá MDR, Castillo MG Cuniberti LA, et al: Novel insights into cardiac regeneration based on differential fetal and adult ovine heart transcriptomic analysis. Am J Physiol Heart Circ Physiol 318: H994-H1007, 2020.

18. Mahmoud AI, Kocabas F, Muralidhar SA, Kimura W, Koura AS, Thet S, Porrello ER and Sadek HA: Meis1 regulates postnatal cardiomyocyte cell cycle arrest. Nature 497: 249-253, 2013.

19. Imamura T, Morimoto A, Takanashi M, Hibi S, Sugimoto T, Ishii $\mathrm{E}$ and Imashuku S: Frequent co-expression of HoxA9 and Meis1 genes in infant acute lymphoblastic leukaemia with MLL rearrangement. Br J Haematol 119: 119-121, 2002.

20. Kimura W, Xiao F, Canseco DC, Muralidhar S, Thet SW, Zhang HM, Abderrahman Y, Chen R, Garcia JA, Shelton JM, et al: Hypoxia fate mapping identifies cycling cardiomyocytes in the adult heart. Nature 523: 226-230, 2015.

21. Yao MZ, Ge XY, Liu T, Huang N, Liu H, Chen Y, Zhang Z and $\mathrm{Hu}$ CP: MEIS1 regulated proliferation and migration of pulmonary artery smooth muscle cells in hypoxia-induced pulmonary hypertension. Life Sci 255: 117822, 2020.

22. Ferreira HJ, Heyn H, Vizoso M, Moutinho C, Vidal E, Gomez A Martínez-Cardús A, Simó-Riudalbas L, Moran S, Jost E and Esteller M: DNMT3A mutations mediate the epigenetic reactivation of the leukemogenic factor MEIS1 in acute myeloid leukemia. Oncogene 35: 3079-3082, 2016.

23. Lasa A, Carnicer MJ, Aventín A, Estivill C, Brunet S, Sierra J and Nomdedéu JF: MEIS 1 expression is downregulated through promoter hypermethylation in AML1-ETO acute myeloid leukemias. Leukemia 18: 1231-1237, 2004.

24. Musialik E, Bujko M, Kober P, Grygorowicz MA, Libura M, Przestrzelska M, Juszczynski P, Borg K, Florek I, Jakóbczyk M and Siedlecki JA: Promoter DNA methylation and expression levels of HOXA4, HOXA5 and MEIS1 in acute myeloid leukemia. Mol Med Rep 11: 3948-3954, 2015.

25. Ropa J, Saha N, Chen Z, Serio J, Chen W, Mellacheruvu D, Zhao L, Basrur V, Nesvizhskii AI and Muntean AG: PAF1 complex interactions with SETDB1 mediate promoter H3K9 methylation and transcriptional repression of Hoxa9 and Meis1 in acute myeloid leukemia. Oncotarget 9: 22123-22136, 2018.

26. Beukers W, Hercegovac A, Vermeij M, Kandimalla R, Blok AC van der Aa MMN, Zwarthoff EC and Zuiverloon TCM: Hypermethylation of the polycomb group target gene $\mathrm{PCDH} 7$ in bladder tumors from patients of all ages. J Urol 190: 311-316, 2013.
27. Dihal AA,Boot A, van Roon EH,Schrumpf M,Fariña-Sarasqueta A, Fiocco M, Zeestraten CM, Peter JK, Kuppen PJK, Morreau H, et al: The homeobox gene Meis1 is methylated in BRAF (p.V600E) mutated colon tumors. PLoS One 8: e79898, 2013.

28. Soltani N, Karimiani EG, Farzanehfar M, Mashkani B,Jafarian A, Ashraf H, Rezyat AA and Soukhtanloo M: Evaluation of the methylation status of the MEIS1 promoter gene in colorectal cancer. Middle East J Cancer 7: 203-207, 2016.

29. Popovic D, Vucic D and Dikic I: Ubiquitination in disease pathogenesis and treatment. Nat Med 20: 1242-1253, 2014.

30. Liu X, Zhang F, Zhang Y, Li X, Chen C, Zhou M, Zhuo Yu, Liu Y, Zhao Y, Hao X, et al: PPM1K regulates hematopoiesis and leukemogenesis through CDC20-mediated ubiquitination of MEIS1 and p21. Cell Rep 23: 1461-1475, 2018.

31. Garcia-Cuellar MP, Steger J, Füller E, Hetzner K and Slany RK: $\mathrm{Pbx} 3$ and Meis1 cooperate through multiple mechanisms to support hox-induced murine leukemia. Haematologica 100: 905-913, 2015.

32. Lawrence HJ, Rozenfeld S, Cruz C, Matsukuma K, Kwong A, Kömüves L, Buchberg AM and Largman C: Frequent co-expression of the HOXA9 and MEIS1 homeobox genes in human myeloid leukemias. Leukemia 13: 1993-1999, 1999.

33. Shen WF, Montgomery JC, Rozenfeld S, Moskow JJ, Lawrence HJ, Buchberg AM and Largman C: AbdB-like hox proteins stabilize DNA binding by the Meis1 homeodomain proteins. Mol Cell Biol 17: 6448-6458, 1997.

34. Williams TM, Williams ME and Innis JW: Range of HOX/TALE superclass associations and protein domain requirements for HOXA13: MEIS interaction. Dev Biol 277: 457-471, 2005.

35. Wermuth PJ and Buchberg AM: Meis1-mediated apoptosis is caspase dependent and can be suppressed by coexpression of Hox A9 in murine and human cell lines. Blood 105: 1222-1230, 2005.

36. Shen WF, Rozenfeld S, Kwong A, Köm ves LG, Lawrence HJ and Largman C: HOXA9 forms triple complexes with PBX2 and MEIS1 in myeloid cells. Mol Cell Biol 19: 3051-3061, 1999.

37. Sarno JL, Kliman HJ and Taylor HS: HOXA10, Pbx2, and Meis1 protein expression in the human endometrium: Formation of multimeric complexes on HOXA10 target genes. J Clin Endocrinol Metab 90: 522-528, 2005.

38. Toresson H, Parmar M and Campbell K: Expression of Meis and $\mathrm{Pbx}$ genes and their protein products in the developing telencephalon: Implications for regional differentiation. Mech Dev 94: 183-187, 2000.

39. Chang CP, Jacobs Y, Nakamura T, Jenkins NA, Copeland NG and Cleary ML: Meis proteins are major in vivo DNA binding partners for wild-type but not chimeric Pbx proteins. Mol Cell Biol 17: 5679-5687, 1997.

40. Bischof LJ, Kagawa N, Moskow JJ, Takahashi Y, Iwamatsu A, Buchberg AM and Waterman MR: Members of the Meis1 and pbx homeodomain protein families cooperatively bind a cAMP-responsive sequence (CRS1) from bovine CYP17. J Biol Chem 273: 7941-7948, 1998.

41. Mojsin M and Stevanovic M: PBX1 and MEIS1 up-regulate SOX3 gene expression by direct interaction with a consensus binding site within the basal promoter region. Biochem $\mathrm{J} 425$ : 107-116, 2009.

42. Dardaei L, Longobardi E and Blasi F: Prep1 and Meis1 competition for $\mathrm{Pbxl}$ binding regulates protein stability and tumorigenesis Proc Natl Acad Sci USA 111: E896-E905, 2014

43. Thorne RMW and Milne TA: Dangerous liaisons: Cooperation between Pbx3, Meis1 and Hoxa9 in leukemia. Haematologica 100: 850-853, 2015 .

44. Okada Y, Nagai R, Sato T, Matsuura E, Minami T, Morita I and Doi T: Homeodomain proteins MEIS1 and PBXs regulate the lineage-specific transcription of the platelet factor 4 gene. Blood 101: 4748-4756, 2003.

45. Rosales-Aviña JA, Torres-Flores J, Aguilar-Lemarroy A, Gurrola-Díaz C, Hernández-Flores G, Ortiz-Lazareno PC, Lerma-DíazJM, de Celis R, González-Ramella Ó, Barrera-Chaires E, et al: MEIS1, PREP1, and PBX4 are differentially expressed in acute lymphoblastic leukemia: Association of MEIS1 expression with higher proliferation and chemotherapy resistance. J Exp Clin Cancer Res 30: 112,2011.

46. Rad A,Farshchian M,Forghanifard MM,Matin MM,Bahrami AR, Geerts D, A'rabi A, Memar B and Abbaszadegan MR: Predicting the molecular role of MEIS1 in esophageal squamous cell carcinoma. Tumour Biol 37: 1715-1725, 2016.

47. Patel AV, Chaney KE, Choi K, Largaespada DA, Kumar AR and Ratner N: An shRNA screen identifies MEIS1 as a driver of malignant peripheral nerve sheath tumors. EBioMedicine 9: 110-119, 2016. 
48. Lin LH, Huang ML, Shi XP, Mayakonda A, Hu KS, Jiang YY, Guo X, Chen L, Pang B, Doan N, et al: Super-enhancer-associated MEIS1 promotes transcriptional dysregulation in ewing sarcoma in co-operation with EWS-FLI1. Nucleic Acids Res 47: $1255-1267,2019$.

49. Cui L, Li M, Feng F, Yang Y, Hang X, Cui J and Gao J: MEIS1 functions as a potential AR negative regulator. Exp Cell Res 328: 58-68, 2014.

50. Yokoyama T, Nakatake M, Kuwata T, Couzinet A, Goitsuka R, Tsutsumi S, Aburatani H, Valk PJM, Delwel R and Nakamura T: MEIS1-mediated transactivation of synaptotagmin-like 1 promotes CXCL12/CXCR4 signaling and leukemogenesis. J Clin Invest 126: 1664-1678, 2016.

51. Argiropoulos B, Yung E, Xiang P, Lo C, Kuchenbauer F, Palmqvist L, Reindl C, Heuser M, Sekulovic S, Rosten P, et al: Linkage of the potent leukemogenic activity of Meis1 to cell-cycle entry and transcriptional regulation of cyclin D3. Blood 115: 4071-4082, 2010.

52. Mohr S, Doebele C, Comoglio F, Berg T, Beck J, Bohnenberger H Alexe G, Corso J, Ströbel P, Wachter A, et al: Hoxa9 and Meis1 cooperatively induce addiction to syk signaling by suppressing miR-146a in acute myeloid leukemia. Cancer Cell 31: 549-562, 2017

53. Thorsteinsdottir U, Kroon E, Jerome L, Blasi F and Sauvageau G: Defining roles for HOX and MEIS1 genes in induction of acute myeloid leukemia. Mol Cell Biol 21: 224-234, 2001.

54. Calvo KR, Knoepfler PS, Sykes DB, Pasillas MP and Kamps MP Meis1a suppresses differentiation by G-CSF and promotes proliferation by SCF: Potential mechanisms of cooperativity with Hoxa9 in myeloid leukemia. Proc Natl Acad Sci USA 98: 13120-13125, 2001.

55. Wang GG, Pasillas MP and Kamps MP: Persistent transactivation by Meis1 replaces hox function in myeloid leukemogenesis models: Evidence for co-occupancy of Meis1-pbx and hox-pbx complexes on promoters of leukemia-associated genes. Mol Cell Biol 26: 3902-3916, 2006

56. Kiyoi H, Kawashima N and Ishikawa Y: FLT3 mutations in acute myeloid leukemia: Therapeutic paradigm beyond inhibitor development. Cancer Sci 111: 312-322, 2020.

57. Jin G, Yamazaki Y, Takuwa M, Takahara T, Kaneko K, Kuwata T, Miyata S and Nakamura T: Tribl and evil cooperate with Hoxa and Meis1 in myeloid leukemogenesis. Blood 109: 3998-4005, 2007.

58. Arabanian LS, Johansson P, Staffas A, Nilsson T, Rouhi A, Fogelstrand L and Palmqvist L: The endothelin receptor type A is a downstream target of Hoxa9 and Meis1 in acute myeloid leukemia. Leuk Res 75: 61-68, 2018.

59. Pineault N, Buske C, Feuring-Buske M, Abramovich C, Rosten $P$, Hogge DE, Aplan PD and Humphries RK: Induction of acute myeloid leukemia in mice by the human leukemia-specific fusion gene NUP98-HOXD13 in concert with Meis1. Blood 101: 4529-4538, 2003.

60. Wang GG, Pasillas MP and Kamps MP: Meis1 programs transcription of FLT3 and cancer stem cell character, using a mechanism that requires interaction with $\mathrm{Pbx}$ and a novel function of the Meis1 C-terminus. Blood 106: 254-264, 2005.

61. Li ZJ, Chen P, Su R, Hu C, Li Y, Elkahloun AG, Zuo Z, Gurbuxani S, Arnovitz S, Weng H, et al: PBX3 and MEIS1 cooperate in hematopoietic cells to drive acute myeloid leukemias characterized by a core transcriptome of the MLL-rearranged disease. Cancer Res 76: 619-629, 2016.

62. Wong P, Iwasaki M, Somervaille TCP, So CWE, So CWE and Cleary ML: Meis1 is an essential and rate-limiting regulator of MLL leukemia stem cell potential. Genes Dev 21: 2762-2774, 2007.

63. Orlovsky K, Kalinkovich A, Rozovskaia T, Shezen E, Itkin T, Alder H, Ozer HG, Carramusa L, Avigdor A, Volinia S, et al: Down-regulation of homeobox genes MEIS1 and HOXA in MLL-rearranged acute leukemia impairs engraftment and reduces proliferation. Proc Natl Acad Sci USA 108: 7956-7961, 2011.

64. Whitlock NC, Trostel SY, Wilkinson S, Terrigino NT, Hennigan ST, Lake R, Carrabba NV, Atway R, Walton ED Gryder BE, et al: MEIS1 down-regulation by MYC mediates prostate cancer development through elevated HOXB13 expression and AR activity. Oncogene 39: 5663-5674, 2020.

65. Johng D, Torga G, Ewing CM, Jin K, Norris JD, McDonnell DP and Isaacs WB: HOXB13 interaction with MEIS1 modifies proliferation and gene expression in prostate cancer. Prostate 79: 414-424, 2019.
66. VanOpstall C, Perike S, Brechka H, Gillard M, Lamperis S, Zhu BZ, Brown R, Bhanvadia R and Griend DJ: MEIS-mediated suppression of human prostate cancer growth and metastasis through HOXB13-dependent regulation of proteoglycans. ELife 9: e53600, 2020.

67. Li W, Huang K, Guo H and Cui G: Meis1 regulates proliferation of non-small-cell lung cancer cells. J Thorac Dis 6: 850-855, 2014.

68. Song F, Wang H and Wang Y: Myeloid ecotropic viral integration site 1 inhibits cell proliferation, invasion or migration in human gastric cancer. Oncotarget 8: 90050-90060, 2017.

69. Zhu J, Cui L, Xu A, Yin X, Li F and Gao J: MEIS1 inhibits clear cell renal cell carcinoma cells proliferation and in vitro invasion or migration. BMC cancer 17: 176, 2017.

70. Mahmoudian RA, Bahadori B, Rad A, Abbaszadegan MR and Forghanifard MM: MEIS1 knockdown may promote differentiation of esophageal squamous carcinoma cell line KYSE-30. Mol Genet Genomic Med 7: e00746, 2019.

71. Grembecka J, He S, Shi A, Purohit T, Muntean AG, Sorenson RJ, Showalter HD, Murai MJ, Belcher AM, Hartley T, et al: Menin-MLL inhibitors reverse oncogenic activity of MLL fusion proteins in leukemia. Nat Chem Biol 8: 277-284, 2012.

72. Borkin D, He S, Miao H, Kempinska K, Pollock J, Chase J, Purohit T, Malik B, Zhao T, Wang J, et al: Pharmacologic inhibition of the Menin-MLL interaction blocks progression of MLL leukemia in vivo. Cancer Cell 27: 589-602, 2015.

73. Kühn MWM, Song E, Feng Z, Sinha A, Chen CW, Deshpande AJ, Cusan M, Farnoud N, Mupo A, Grove C, et al: Targeting chromatin regulators inhibits leukemogenic gene expression in NPM1 mutant leukemia. Cancer Discov 6: 1166-1181, 2016.

74. Klossowski S, Miao H, Kempinska K, Wu T, Purohit T, Kim E, Linhares BM, Chen D, Jih G, Perkey E, et al: Menin inhibitor MI-3454 induces remission in MLL1-rearranged and NPM1-mutated models of leukemia. J Clin Invest 130: 981-997, 2020.

75. Krivtsov AV, Evans K, Gadrey JY, Eschle BK, Hatton C, Uckelmann HJ, Ross KN, Perner F, Olsen SN, Pritchard T, et al: A menin-MLL inhibitor induces specific chromatin changes and eradicates disease in models of MLL-rearranged leukemia. Cancer Cell 36: 660-673, 2019.

76. Gundry MC, Goodell MA and Brunetti L: It's all about MEis: Menin-MLL inhibition eradicates NPM1-mutated and MLL-rearranged acute leukemias in mice. Cancer Cell 37: 267-269, 2020.

77. Uckelmann HJ, Kim SM, Wong EM, Hatton C, Giovinazzo H, Gadrey JY, Krivtsov AV, Rücker FG, Döhner K, McGeehan GM, et al: Therapeutic targeting of preleukemia cells in a mouse model of NPM1 mutant acute myeloid leukemia. Science 367: 586-590, 2020.

78. Xu S, Aguilar A, Xu T, Zheng K, Huang L, Stuckey J, Chinnaswamy K, Bernard D, Fernández-Salas E, Liu L, et al: Design of the first-in-class, highly potent irreversible inhibitor targeting the Menin-MLL protein-protein interaction. Angew Chem Int Ed Engl 57: 1601-1605, 2018.

79. Chen WL, Li DD, Chen X, Wang YZ, Xu JJ, Jiang ZY, You QD and Guo XK: Proton pump inhibitors selectively suppress MLL rearranged leukemia cells via disrupting MLL1-WDR5 protein-protein interaction. Eur J Med Chem 188: 112027, 2020.

80. Zhang L, Chen Y, Liu N, Li L, Xiao S, Li X, Chen K, Luo C, Chen S and Chen H: Design, synthesis and anti leukemia cells proliferation activities of pyrimidylaminoquinoline derivatives as DOT1L inhibitors. Bioorg Chem 80: 649-654, 2018.

81. Somers K, Chudakova DA, Middlemiss SMC, Wen VW, Clifton M, Kwek A, Liu B, Mayoh C, Bongers A, Karsa M, et al: CCI-007, a novel small molecule with cytotoxic activity against infant leukemia with $M L L$ rearrangements. Oncotarget 7: 46067-46087, 2016.

82. Turan RD, Albayrak E, Uslu M, Siyah P, Alyazici LY, Kalkan BM, Aslan GS, Yuce DC, Aksoz M, Tuysuz EC, et al: Development of small molecule MEIS inhibitors that modulate HSC activity. Sci Rep 10: 7994, 2020.

83. Vander Heiden MG, Cantley LC and Thompson CB: Understanding the warburg effect: The metabolic requirements of cell proliferation. Science 324: 1029-1033, 2009.

This work is licensed under a Creative Commons Attribution-NonCommercial-NoDerivatives 4.0 International (CC BY-NC-ND 4.0) License. 